\title{
BACCIO DEL BIANCO Y LOS PINTORES ESCENÓGRAFOS DE MADRID: MUTACIONES PARA TRIUNFOS DE AMOR Y FORTUNA (1655-1658), FIESTA REAL DE ANTONIO DE SOLÍS
}

\author{
María Asunción Flórez Asensio \\ (Investigadora independiente) \\ maflorezasensio0@,outlook.es
}

\section{RESUMEN}

Considerado inicialmente un trabajo menor, la ejecución de decorados teatrales evolucionó a lo largo del siglo XVII al implicar progresivamente a artistas de prestigio. Así lo demuestra la puesta en escena de Triunfos de Amor y Fortuna. Ideada en 1655 por Baccio del Bianco para festejar los años de Felipe IV, sus mutaciones se encomendaron inicialmente a tres artistas hoy prácticamente desconocidos. Retrasada la representación hasta 1658, muerto ya su creador, fueron terminadas por Francisco Rizi bajo la supervisión de Antonio María de Antonozzi, que parece haber seguido los diseños de Baccio, pues apenas hay cambios en el proyecto. Así se desprende de la comparación que hacemos en este trabajo entre las mutaciones encargadas en 1655 y las que finalmente se hicieron para su representación en 1658, descritas minuciosamente en las acotaciones de las ediciones de la fiesta.

PALABRAS CLAVE: Baccio del Bianco; Triunfos de Amor y Fortuna; pintores escenógrafos; Francisco Rizi.

\section{BACCIO DEL BIANCO AND THE SCENOGRAPHER PAINTERS OF MADRID: SET DESIGNS FOR TRIUNFOS DE AMOR Y FORTUNA (1655/1658), ANTONIO DE SOLÍS ROYAL FEAST}

\begin{abstract}
Initially considered a minor work, the execution of theatrical sets evolved throughout the 17 th century, progressively involving prestigious artist. This is demonstrated by the staging of Triunfos de Amor y Fortuna. Conceived in 1655 by Baccio del Bianco to celebrate the king's years, its set designs were initially entrusted to three artists practically unknown today. Delayed representation until 1658, already dead its creator, they were finished by Francisco Rizi under Antonio María de Antonozzi supervision, who seems to have followed Baccio's designs, since there are hardly any changes in the project. This is clear from the comparison we make in this work between the set designs commissioned in 1655 and those that were finally
\end{abstract}


made for their representation in 1658 , described in detail in the dimensions of the festival editions.

KEY WORDS: Baccio del Bianco; Triunfos de Amory Fortuna; Scenographer Painters; Francisco Rizi.

Aunque las novedades escenográficas desarrolladas en Italia no eran desconocidas en la corte española, la llegada al trono de Felipe IV marca una nueva etapa debido a la presencia en Madrid de algunos de los mejores arquitectos teatrales italianos del momento ${ }^{1}$. Cuatro fueron concretamente los que trabajaron para el rey: Julio Cesar Fontana, Cosme Lotti, Baccio del Bianco y Antonio María de Antonozzi. Pero si todos ellos disfrutaron de reconocimiento, sólo Lotti y, sobre todo, Baccio del Bianco alcanzaron una popularidad que las propias obras teatrales reflejan:

$\begin{array}{ll}\text { POLINIO: } & \text { ¿Cielos, que horrenda cosa! } \\ \text { BATO: } & \text { ¿Quién así te tiene? } \\ \text { POLINIO: } & \text { ¿Por qué? } \\ \text { BATO: } & \text { Corce. } \\ \text { POLINIO: } & \text { ¿Y quién fue la cautoja. } \\ \text { BATO: } & \\ \text { POLINIO: } & \text { ¿Cómo? } \\ \text { BATO: } & \text { Por Bacho. } \\ & \end{array}$

\footnotetext{
${ }^{1}$ De hecho, la «práctica escénica cortesana está bien establecida antes de la llegada de Lotti y Fontana, cuyos trabajos vinieron a incorporarse a ella, desarrollándola.» Teresa Ferrer Valls, La práctica escénica cortesana: de la época del Emperador a la de Felipe III (London: Támesis, 1991), 81. Los primeros espectáculos teatrales cortesanos de la Edad Moderna, representados en teatros efímeros diseñados por los arquitectos reales, mostraron ya algunos ejemplos de escenografía en perspectiva. Fue el caso de la "pintura de una muy perfecta ciudad [Londres] puesta en muy buena perspectiva en las calles, casas, y plaça, y ventanas [...] aunque era el sitio breue, se remediaua este inconueniente con la subtileza, traça y buen ingenio del architecto y pintor.» Relación de la representación de Amadis de Gaula en Burgos en 1570 para recibir a la reina Ana de Austria. Ver Norman D. Shergold, A History of the Spanish Stage from Medieval times until the end of the Seventeenth Century (Oxford: Clarendon Press, 1967), 242 , n. 2.

${ }^{2}$ Pico y Canente. Fiesta que la Serenísima infanta Doña Maria Teresa de Austria mandó haz̧er, en celebración de la salud de la Reyna nuestra Señora Doña Mariana de Austria. Executose en el Salón del Palacio de el Buen Retiro y después en su Coliseo. Jornada III, p. 24. Cito por la suelta que se conserva en la Biblioteca Nacional de España (BNE), T-20695. Escrita en colaboración por cinco poetas (Luis de Ulloa, Diego de Silva, Rodrigo de Ávila, Juan Riao y Antonio de Solís), Baccio tuvo que satisfacer, en lo posible, todas sus «bestialissime domande» según comenta en carta fechada el 3/3/1656 al Gran Duque Fernando II. Ver Mina Bacci, “Lettere inedite di Baccio del Bianco", Paragone 157 (1963): 68-77, 74.
} 
Apenas instalado en la villa y corte, Baccio asume la puesta en escena de La fiera, el rayo y la piedra (1652), escrita por Calderón para celebrar los años de la joven reina Mariana de Austria. Pese a los recelos iniciales del dramaturgo ante la complejidad de la propuesta del italiano, la fiesta fue todo un éxito ${ }^{3}$, y no sólo de público ya que le granjeó la admiración de los profesionales del teatro: «ho acquistato molta amicizia e di musici e comedianti e poeti, che veduto esser riuscite le tramoie ogni giorno mi vengono a proporre nuove cose» ${ }^{4}$. También conquistó la del marqués de Heliche, figliolo de don Luis de $\mathrm{Haro}^{5}$, que empezaba en esta época (todavía por delegación de su padre) a asumir la responsabilidad de supervisar los espectáculos cortesanos. Por su formación en la Casa de Contratación de Sevilla ${ }^{6}$, el marqués estaba perfectamente capacitado para comprender el genio del italiano, considerado «el Dédalo destos tiempos, que sin hipérboles se aventaja con verdad al que por famoso celebró la antigüedad en el tan decantado laberinto de Creta» ${ }^{7}$.

$\mathrm{Al}$ año siguiente el tándem Calderón-Baccio protagonizó otro gran éxito: la puesta en escena de Fortunas de Andrómeda y Perseo, patrocinada por la infanta María Teresa y todavía bajo la responsabilidad -al menos formal- de Haro ${ }^{8}$. Siguiendo el modelo de La fiera, el rayo y la piedra, la nueva obra consolidará el de la fiesta real

\footnotetext{
${ }^{3}$ Representada «en el Palacio del Buen Retiro en su Coliseo, destinado para grandes fiestas, y esta fue sin duda festiuisima, y vna de las mayores, que se han visto en Europa». BNE, Mss. 2384: Escrivense los sucesos de la Europa y otras partes desde el abril de 1652 hasta el Marco de 1653, p. 42. Para la doble función del Coliseo como teatro cortesano y público ver María Asunción Flórez Asensio, "El Coliseo del Buen Retiro en el siglo XVII: teatro público y cortesano", Anales de Historia del Arte 8 (1998): 171-195.

${ }^{4}$ Carta de Baccio de 4/8/1652. Archivio di Stato, Florencia (ASF), Mediceo del Principato, filza 5.450. Cito por María Teresa Chaves Montoya, El espectáculo teatral en la corte de Felipe IV (Madrid: Ayuntamiento de Madrid, 2004), 247, n. 170.

${ }^{5}$ Valido del rey, se había encargado personalmente de gestionar la contratación del florentino con el embajador toscano. De hecho, Baccio era consciente de la importancia diplomática de su misión: "piaccia a Dio che mi tenga di su' mano acciò faccia onore alla patria e utille alla mia casa». Carta de Baccio fechada el 3/3/1656. Ver Bacci, "Lettere", 77.

${ }^{6}$ Allí había estudiado «las partes de matemáticas que llaman arquitectura militar» y también «lo teórico de la navegación [...] lo prá[c]tico en el conocimiento de las partes fábricas y composiçión de la nao con su apresto». Auto de calificación del examen de arquitectura militar (24/3/1646). Archivo General de Indias (AGI), Contratación, leg. 5781, no 59, fols. 218v-219r. Cito por Felipe Vidales del Castillo, "El VII marqués del Carpio y las letras" (Tesis doctoral, Universidad Complutense, 2016) 76. Creo muy probable que Heliche encabezase por propia iniciativa el grupo de «primi cavalieri della corte» que, según Baldinucci, ayudaron a Baccio a manejar la maquinaria ante la falta de oficiales expertos. Filipo Baldinucci, Notizie dei professori del disegno da Cimabue in qua (Fiorenza: Batelli, 1847). Edic. facsímil Spes: Florencia, 1974, vol. V, 7-51, 48.

7 BNE, Mss. 2384: Escrivense los sucesos de la Europa y otras partes desde el abril de 1652 hasta el Marco de 1653, p. 42. Enviado por Fernando II, Gran Duque de Toscana, en respuesta a la petición de Felipe IV que, tras su segundo matrimonio, deseaba recuperar la brillante época protagonizada en los primeros años de su reinado por Cosme Lotti, cuando llega a Madrid es ya un artista en plena madurez personal (había nacido en 1604) y con una asentada carrera profesional en campos muy diversos. Ver Baldinucci, Notizie, 30 y Dizionario Biografico degli Italiani (Roma: Istituto dell'Enciclopedia Italiana, 1988), pp. 348-349, 348.

${ }^{8}$ Ver María Asunción Flórez Asensio, "El marqués de Liche: Alcaide del Buen Retiro y "Superintendente" de los Festejos Reales", Anales de historia del arte 20 (2010): 145-182, 157.
} 
cantada, unión de Poesía, Pintura y Música, como afirma el propio Calderón en la loa ${ }^{9}$. Por deseo de Mariana de Austria (la obra fue representada para celebrar su recuperada salud), que quiso enviar noticia de ella a su padre el emperador Fernando III, el texto, la música y los bocetos escenográficos (encargados al propio Baccio) ${ }^{10}$ se recogieron en un manuscrito, conservado hoy en la Hougthon Library de la Universidad de Harvard $^{11}$. Solitaria muestra del trabajo escénico realizado en España por el italiano, comparte muchas soluciones con las ideadas por Baccio del Bianco para Triunfos de Amory Fortuna de Antonio de Solís ${ }^{12}$, dramaturgo muy apreciado por don Pedro ${ }^{13}$, con el que -pese a su perfecta simbiosis con Calderón ${ }^{14}$ - comenzará a trabajar apenas iniciado 1654 con la puesta en escena de Euridice y Orfeo, representada durante el Carnaval:

con l'aiuto di Dio, non m'è succeduto male. Solo a la comedia del Carnoval passato, oggi un anno, il maestro di cappella dietro alle scene, andando con furia cadde in un pozzo

\footnotetext{
${ }^{9}$ Fusión de los «rasgos deste pincel /.../ en vistosas perspectiuas» de la Pintura, con las «fantasías» de la Música, y los «estudios» de la Poesía que dan «a tus coros y a tus líneas / el alma que han de tener». Pedro Calderón de la Barca, Andrómeda y Perseo. Edición filológica, crítica y escenotécnica de Rafael Maestre (Almagro: Museo Nacional del Teatro, 1994), 43 y 44, vv. 56, 61, 71, 79-80, 87-88, aunque no los cito en este orden. No se trata, pues, de un mero espectáculo ya que la intención es transmitir un profundo contenido moral y político.

10 «è piaciuta [la comedia] (e per la mia parte e per la parte del poeta) assai piú della dell'anno passato [...] le macchine erano in quantità e assai buone, con voli d'ogni sorta, precipizzi e quello che voglion qua [...]. Si è fatta circa 30 volte all pubblico [...], e quando pensavo riposare, mi comandò sua Maestà i disegni delle scene per mandare con la commedia e musiche allimperatore che son stati 11 pezzi di disegno come di stampa.» Carta de 19/7/1653. Ver Bacci, "Lettere", 71-72.

${ }^{11}$ Mss. Typ 258 H. Hay edición facsímil del Museo Nacional del Teatro (Almagro) a cargo de Rafael Maestre, por la que hago todas las citas. Fueron dados a conocer por Phyllis Dearborn Massar, "Scenes for a Calderón Play by Baccio del Bianco" Master Drawings 15 (1977) 365-375. Los dibujos de Baccio son fácilmente accesibles en red. Pueden verse comentados en Blog de Bibliofilia, http://blogdebibliofilia.blogspot.com/2012/07/andromeda-y-perseo.html.

12 Perteneciente a una familia de hidalgos castellanos, en 1651, tras pasar algunos años al servicio del conde de Oropesa, se instala definitivamente en Madrid, en un momento muy propicio para el desarrollo de su carrera como dramaturgo. Ver su biografía en Fréderic Serralta, "Nueva Biografía de Antonio de Solís y Rivadeneyra", Criticón 34 (1986): 51-157.

${ }_{13}$ Ambos, junto con Antonio Coello, colaborarán en la comedia Elpastor Fido, que recrea la muy conocida obra de Gian Battista Guarini. Su representación suele fijarse entre 1650 y 1651. Ver Marcella Trambaioli. "La escritura en colaboración en Elpastor Fido de Solís, Coello y Calderón", en Calderón y su escuela: variaciones e innovación de un modelo teatral. XV Coloquio Anglogermano sobre Calderón (Wrodaw, 14-18 de julio de 2008), ed. Manfred Tietz y Gero Arnscheidt, en colaboración con Beata Baczynska (Stuttgart: Franz Steiner Verlag, 2011), 493-521.

${ }^{14}$ Según Maestre, hay siempre una gran coherencia entre la «instrumentación tecnológica» de los espectáculos mitológicos del dramaturgo madrileño y su «naturaleza dramática», hasta el punto de que Del Bianco trabajará «simbióticamente con Calderón, enfatizando las diferentes artes». No sucederá lo mismo con otros dramaturgos, cuyas incongruencias escénicas, anticuadas convenciones e incorrecciones temáticas supondrán un obstáculo para el florentino, que calificara sus peticiones de bestialisimas. Ver Rafael Maestre, "Calderón de la Barca-Baccio del Bianco: un binomio escénico", Revista de Historia Moderna 11 (1992): 239-250, 240, 242 y 244.
} 
a dove calavano contrappesi di un volo di Euridice e poco mancò che non finì le sue composizzioni ${ }^{15}$.

En 1655 Baccio vuelve a colaborar con Solís ideando la puesta en escena de Triunfos de Amor y Fortuna, programada inicialmente para celebrar los años de Felipe IV, que (nacido el 8 de abril de 1605) entraba ese año en la cincuentena. Apenas dos meses antes del cumpleaños real, el florentino escribía al gran duque Fernando II disculpándose por la «non volontaria colpa» en darle noticias de su actividad en la corte madrileña. También le informaba de que en ese momento se encontraba ocupado haciendo «i modelli delle tramoie» para una comedia escrita por Don Antonio de Solís,

poeta famoso, parte cantata e parte recitata et il suggetto è Psiche per una parte annessa la favola con la [storia] di Indimione. [...]. La comedia è tutta movimiento per aria, mutazzioni, voli, rovine, tutte cose che qua piacciono [...]. Son questi spagnioli desiosi di novita, di macchine violente, precipitose, ratte, a segnio che io mi sono arrischiato a cose che costà non si sarebbero comportate e sino a ora, con l'aiuto di Dio, non m'è succeduto male ${ }^{16}$.

Como ingeniero-escenógrafo su tarea consistía en idear las tramoyas en las que aparecen y desaparecen los actores, diseñar las mutaciones (decorados en perspectiva) e inventar los dispositivos que permitían cambiarlos con la mayor celeridad, incluso a la vista del público, trazando las soluciones mecánicas ${ }^{17}$ pero sin implicarse físicamente -a diferencia de lo que sucederá con los pintores-escenógrafos españoles que le sucedieron ${ }^{18}$ - en su elaboración. Este trabajo, que incluía la ejecución de los paramentos (generalmente al temple) sobre grandes lienzos, así

${ }^{15}$ Carta de 5/2/1655. Ver en Bacci, "Lettere", 73. Las cursivas son mías. Este dato parece haber pasado desapercibido ya que Serralta ("Nueva Biografía", 89), apoyándose en las personas reales citadas en la loa (escrita también por Solís), da como posible fecha para la representación de Euridice y Orfeo el sábado de Carnaval, pero de 1655. El maestro de la Real Capilla era en esa época Carlos Patiño, también autor de tonadas o canciones de cámara profanas que, finalmente, y según Baccio, «gli risulto bene perché sua M. gli diede 400 ducati di pensione».

${ }^{16}$ Carta de 5/2/1655. Ver en Bacci, "Lettere”, 72-73. Las cursivas son mías.

${ }^{17}$ Así lo confirma Francesco Ottonelli al informar al duque de Módena de cómo el florentino, que era «il direttore et fabricatore delle machine et delle scene», perdía «la scherma con questi operari che non sanno eseguire ciò che egli disegna». Carta de 10/5/1653. Ver Salvador Salort Pons, Velázquez en Italia (Madrid: Fundación Arte Hispánico, 2002), 484, doc. b50. Las cursivas son mías. También disponía las luces, aplicando a la escenografía teatral técnicas pictóricas novedosas como el claroscuro de los tenebristas.

${ }^{18}$ Fue el caso de Herrera el Mozo. En 1672 se ocupó de «la obra del teatro pintado q[ue] hiço en el Salón de Palacio para la comedia que se ha de representar en él a los años del Rey ntro. Sr.» Archivo General de Palacio (AGP), Administrativa, C ${ }^{a}$ 9407, expte. 2, fol. 646r. Nómina de gastos ocasionados por la comedia de los años del rey. Parece que había presentado una «memoria de calidades» para «el teatro que está pintando» que no incluía «la fortificaçion y seguridad de todas la mutaciones y tramoyas por no tocarle a él esta parte». AGP, Administrativa, C $C^{a}$ 9407, expte. 1. Nota del duque del Infantado a D. Gaspar de Legasa (26/9/1672) en papel suelto. Las cursivas son mías. 
como los elementos corpóreos, requería artistas cualificados, buenos conocedores de las leyes de la perspectiva pues, como señala Palomino,

haber de hacer una perspectiva, que parezca pintada en un lienzo solo, estando disipado en muchos, colocados a diferentes distancias; es verdaderamente arduísimo empeño [...] y más cuando en los teatros, por la variedad de las mutaciones, suelen estar las bambalinas [...] muy considerablemente apartadas de los mismos lienzos ${ }^{19}$.

Sin embargo y pese a su dificultad, era despreciado por algunos profesionales $^{20}$, por lo que solían ser pintores bastante secundarios en el panorama artístico cortesano los que lo realizaban. Ese fue el caso en 1655, al encomendarse la ejecución de las mutaciones de Triunfos de Amor y Fortuna a tres artistas de segundo nivel en la escena madrileña: Juan Bautista Sánchez (3 mutaciones), Juan de Toledo (2 mutaciones) y Francisco Rico (4 mutaciones). Sabemos cuál fue la tarea encargada a cada uno gracias a una Relación de los Maestros pintores que se an encargado y an tomado por su quenta a toda costa la obra de pintura, que se a de hacer para las apariencias y tramoyas de la comedia que se a de representar en el Coliseo de Buen Retiro en este presente año de 1655 a la fiesta de los años del Rey n[uest] ro señor, en conformidad de lo ajustado con ellos por el Marqués de Liche mi s[eñ]or ${ }^{21}$. Según la misma el trabajo se distribuyó de la siguiente manera:

19 Antonio Palomino, El museo pictórico y escala óptica (Madrid: Aguilar, 1947), vol. II, 337.

20 Palomino cita el caso de Antolínez, discípulo de Francisco Rizi (ejecutor él mismo de decorados para fiestas palaciegas pese a ser uno de los principales pintores del panorama artístico madrileño), quien quiso darle una lección dándole a pintar «un lienzo al temple, mandando que nadie le advirtiese nada; estuvo todo el día Antolínez haciendo y deshaciendo, al cabo de lo cual le dijo Rizi: ¿Ve aquí vuesa merced lo que es pintar paramentos? Anda muchacho (le dijo a un muchacho) y lava ese lienzo en aquel pilón; y así se ejecutó», quedando corrido el otro y castigada su vanidad. Antonio Palomino, Museo Pictórico y Escala Optica. III. El Parnaso Español Pintoresco Laureado (Madrid, 1724). Edición de Nina Ayala Mallory, Vidas [El Parnaso Español (Madrid: Alianza, 1986), 244. Como señala González-Román «en la valoración que se hacía en la época de la actividad de los artistas, la categoría y distinción social de estos dependía en gran medida de su relación con alguna de las tres artes nobles, de la clientela que les encargaba las obras o, especialmente cuando se trataba de un artista de segunda fila, de su vínculo con la institución monárquica a través del desempeño de algún cargo. Difícilmente será reconocida la actividad como escenógrafo de un artista de escaso renombre, aunque con dicha actividad llegara a vivir de forma incluso desahogada». Carmen González-Román, "El artista escenógrafo: una especialidad no reconocida en la Edad Moderna", en Correspondencia e integración de las Artes: XIV Congreso nacional de Historia del Arte (Málaga, 18-21 de septiembre), ed. Isidoro Coloma Martín, María Teresa Sauret Guerrero, Belén Calderón Roca, Raúl Luque Ramírez, Vol. 1, Málaga: Universidad de Málaga, 2003), 207-223. En línea: https://www.academia.edu/20001780/El artista escen \%C3\%B3grafo una especialidad no recono cida en la Edad Moderna, p. 3. (consultado el 14 diciembre 2020).

${ }^{21}$ Firmada por Alejo de Escalada, montaba «la costa de toda la dicha obra de pintura en la conformidad referida cinquenta y dos mil y tre[s]cientos Reales. F[ec]ho en Madrid a 8 de abril de 1655». Archivo Duque de Alba /Fundación Casa de Alba (ADA), Carpio, Caja 145, $\mathrm{n}^{\circ}$ 13, sin foliar. Ver Anexo. 
Jornada I:

1. Selva de los Hados (Sánchez)

2. Selva de Diana (Toledo)

Jornada II:

3. Palacio de la Fortuna (Rico)

1. Salón Real [del Amor] ${ }^{22}$ (Rico)

2. Ruinas de edificios (Toledo)

Jornada III:

3. Palacio y jardín de Psique (Rico)

1. Escena pastoril con chozas (Sánchez)

2. Mar y puerto con dos palacios (Sánchez)

3. Nubes [o Cielo] (Rico)

Desconocemos los motivos por los que la fiesta no se representó en la fecha prevista, retrasándose el estreno hasta 1658. Ese año y para celebrar el nacimiento de Felipe Próspero, el ansiado príncipe heredero, se programaron numerosos festejos, entre ellos «una famosa comedia, con machine, che da molto tempo si era destinata per questa occasione di publica allegrez:a(a) ${ }^{23}$. Es probable que fuese idea de Heliche rescatarla ${ }^{24}$, dada su condición de auténtico superintendente de un festejo ${ }^{25}$ que influiría en su nombramiento en septiembre de $1658^{26}$ como alcaide titular del Retiro en sustitución de su padre, pues, siendo un admirador confeso del italiano ${ }^{27}$, cuyos dibujos coleccionaba, posiblemente guardaba una copia en su famosa biblioteca ${ }^{28}$.

\footnotetext{
22 Según las acotaciones de la edición de Ulloa, en la representación de 1658 se repitió aquí la «Selva o bosque de los Hados» de la Jornada I, pasando este «Salón Real» a ser la segunda mutación de la II Jornada al desaparecer la de «Ruinas de edificios».

23 Archivio Segreto Vaticano, Roma (ASV), Segr. Stato, Spagna, n. 114. Aviso de la Nunciatura, fechado en Madrid el 28/11/1657. Cito por Chaves Montoya, El espectáculo teatral, 263 y 311, n. 2. Las cursivas son mías.

${ }^{24}$ Ver Flórez Asensio, "El marqués de Liche", 160. Vidales del Castillo ("El VII marqués del Carpio", 92-93) apunta, incluso, que «sabiendo de la obsesiva intención del marqués por controlar todos los aspectos de la fiesta y de sus buenos conocimientos y gusto matemático y sobre ingeniería no es osado pensar que también quisiera tomar partido en esta parte más técnica de la organización».

${ }^{25}$ Clara constancia de ello deja Ulloa y Pereira en su relación de los festejos, publicada en Madrid en 1658. Luis Ulloa y Pereira, Fiestas que se celebraron en la Corte por el Nacimiento de Don Felipe Prospero, Príncipe de Asturias. Hace memoria dellas al Rey nuestro señor (Dios le guarde) poniéndolas en las manos del Excelentísimo Señor Marqués de Heliche Don Luis de Ulloa, (Madrid, 1658).

${ }^{26}$ Ver AGP, Sec. Administrativa, C $C^{a} 11730$, s.f., y también Flórez Asensio "El marqués de Liche", 152.

${ }^{27}$ Muerto Baccio en junio de 1657, Heliche todavía recordaba en 1661 ante el embajador toscano «quanto li fosse doluta la sua morte». ASF, Mediceo del Principato, filza 4.976. Carta del embajador Vieri d'Castiglione fechada el 3/8/1661. Cito por Chaves Montoya, El espectáculo teatral,254, n. 274.

28 Tasado en 100 reales y sin especificar a qué obras corresponden, se consigna «Un tomo en que ay gran cantidad de Dibujos de Bacho del Bianco», [signatura E-1471]. Archivo Histórico de Protocolos de Madrid (AHPM), Po 9819: Imbentario de los vienes que quedaron a la Muerte del Excelentísimo Señor Don Gaspar de Haro y Guzmán marqués del Carpio. Año de 1688 (fols. 741 y ss). Ver Vidales del Castillo, "El VII marqués del Carpio", vol. II, 297. Este inventario, según Vidales del Castillo ("El VII marqués del Carpio", 652), «recoge los libros que Carpio tuvo hasta su marcha en Madrid en 1674, algunos de los que pudo enviar desde Italia» y parte de la colección de manuscritos.
} 
Pero en esta ocasión la realización de las mutaciones se encargó a Francisco Rizi ${ }^{29}$, «pintor de su Magd.», que recibió 11.000 reales a finales de 1657 «para continuar con la pintura de las perspectivas de la comedia grande que estaba empeçada tres años $a\rangle^{30}$. Finalmente parece que fueron 14.300 reales los pagados por el gasto en la «comedia grande que se continua en el Coliseo de Buen Retiro desde 22 de s[eptiemb]re de $1657 »^{31}$.

Según se desprende de los admirados comentarios de la época, el resultado final no tuvo que desmerecer en nada a la idea original de Baccio, muerto en el verano de 1657, por lo que todo el mérito se atribuyó al nuevo ingeniero real, Antonio María Antonozzi,

romano, celebre ingeniero de nuestro siglo, adelantando maravillosamente el Arte de los famosos Cosmelot, y Baccie Bianco, florentinos, bien conocidos en España; ostentó su rara capacidad en la disposición de innumerables tramoyas; mudándose a la luz de infinitos faroles, tantas veces el teatro en diversas perspectivas, y peregrinos aparatos de bien imitado cielo, sol, luna, estrellas, ligeras nubes, fingidos mares, vistosos baxeles, floridos prados, cristalinas fuentes, notables edificios, ricos palacios, deliciosos jardines, y transformaciones increíbles de figuras diferentes, que en instantáneos buelos, artificiosos bayles, suaves músicas y gustosos entremeses, pusieron el Non plus Vltra a la admiración ${ }^{32}$.

No obstante, comparando la descripción que la Relación de 1655 hace de las mutaciones asignadas a cada pintor con las que finalmente se hicieron para su representación en 1658, descritas minuciosamente en las acotaciones de las ediciones

\footnotetext{
${ }^{29}$ Según Frutos, Rizi se habría ocupado de la escenografía, perspectivas y decorados tras la muerte de Lotti pero, al no estar su trabajo a la altura del de los italianos, fue desplazado primero por Baccio del Bianco y después por Mantuano. Leticia Frutos, El templo de la fama. Alegoría del marqués del Carpio (Madrid: Fundación Caja Madrid-Fundación Arte Hispánico, 2009), 41-42. Para su biografía ver Alfonso Emilio Pérez Sánchez, Carreño, Rizzi, Herrera y la pintura madrileña de su tiempo (Madrid: Museo del Prado, 1986), 92-101 y 266-326; y del mismo autor "Los pintores escenógrafos en el Madrid del siglo XVII", en La escenografía del teatro barroco, coord. Aurora Egido, (Salamanca: UIMP, 1989) 61-90, 75-78; y "Rizi de Guevara, Francisco", en Diccionario Biográfico Español, (Madrid: RAH, 2013), vol. XLIII, 648-651. Ver también Palomino, El Parnaso Español, 276-279.

${ }^{30}$ El apunte lleva fecha de 20/12/1657. Archivo General de Simancas (AGS), Contaduría Mayor de Cuentas, Tribunal Mayor de Cuentas, Lego . 3.766. Ver en José María Azcarate, "Anales de la construcción del Buen Retiro", Anales del Instituto de Estudios Madrileños I (1966), 99-135, 134. Las cursivas son mías.

31 Así lo indica una cuenta fechada el 5/1/1658, firmada por Alejo de Escalada (contador del Retiro). Según la misma el Rey había ordenado librar 94.000 reales de vellón (20.000 de ellos por cuenta de gastos secretos), 76.090 de los cuales se gastaron en la comedia y 17.428 en «reparar del sitio». ADA, Carpio, Caja 145, $\mathrm{n}^{\circ} 13$, sin foliar.

32 Rodrigo Méndez Silva, Gloriosa celebridad de España en el nacimiento y solemne bautismo de su amado príncipe Felipe Próspero (Madrid, 1658), fol. 32r. Cito por Chaves Montoya, El espectáculo teatral, 271-272. Para la biografía de Antonozzi ver Juan Ramón Sánchez del Peral y López, “Antonio María Antonozzi, ingeniero de las comedias del Buen Retiro (1657-1662). Nuevos datos para la biografía de un inventor de “maravillosas apariencias"”, Archivo español de arte LXXX/319 (2007), 261-273.
} 
de la fiesta ${ }^{33}$, parece evidente que Antonozzi pudo aprovechar los diseños de Baccio de Bianco pues apenas hay cambios en el proyecto, salvo la loa (escrita siempre expresamente para la ocasión que se celebra) y la escena de la jornada II desarrollada en una mutación de «Ruinas de edificios», que no aparece en la versión definitiva. Por ello y dado que tenemos una información, aunque somera, de cómo eran inicialmente y también del resultado final, podemos intentar compararlas con soluciones semejantes de Baccio para Fortunas de Andrómeda y Perseo pues la mayoría (salvo la de infierno) se repiten en Triunfos: aldea rústica, gruta, «retrete» o sala privada, selva, palacio con jardín, marina, y gloria; y también con otras obras conocidas del florentino. El resultado nos permitirá hacernos una idea de su complejidad y magnificencia, tan alabadas por los contemporáneos.

\section{JUAN BAUTISTA SÁNCHEZ}

Tres fueron las mutaciones o «teatros» encomendados a Juan Bautista Sánchez (¿?-1673), un pintor del que apenas tenemos noticias, aunque en estas fechas tenía ya bastante experiencia dado que en 1624 figura como tal al ser recibido en la Cofradía del Santísimo Sacramento ${ }^{34}$, sita en la parroquia de San Sebastián; en donde fue enterrado tras su muerte, acaecida el $1^{\circ}$ de mayo de $1673^{35}$. Pérez Sánchez cita algunos de sus «modestos trabajos» teatrales como «la pintura que ha de hacer» para la comedia que iban a representar los criados de la Reina en el Salón Grande en $1629^{36}$, cuya puesta en escena fue posiblemente obra de Cosme Lotti ${ }^{37}$; o los cinco

33 Además de un manuscrito en el que se recoge el reparto original, conservado en la BNE (Mss. 16298), y que presenta notables diferencias con las ediciones impresas, la obra nos ha llegado a través de ocho impresos, un número inusual. Ver María del Mar Puchau de Lecea, Antonio de Solís y Rivadeneyra. Triunfos de Amor y Fortuna. Estudio y edición crítica, con transcripción poético-musical de las piezas conservadas de Lola Josa y Mariano Lambea (Aula Música Poética) (Alicante: Biblioteca Virtual Miguel de Cervantes, 2013), 69, http://www.cervantesvirtual.com/nd/ark:/59851/bmc001v8 (consultado en mayo 2020). Las fuentes directamente relacionadas con la representación de 1658 parecen ser la relación de Ulloa (1658), posiblemente la más cercana a la representación; y la suelta Triunfos de amor y fortuna. Fiesta real que se representó a sus Majestades en el Coliseo del Buen Retiro... (Madrid, 1658), sin editor conocido pero cuyo texto apenas se desvía del de Ulloa. Ambas incluyen todas las piezas breves. Ver Puchau, Antonio de Solis, 75-76. Para las restantes fuentes impresas (3 del siglo XVII, 2 del XVIII y 1 de difícil datación) ver Puchau, Antonio de Solís, 73-76; y Manuela Sánchez Regueira, Comedias de Antonio de Solís (Madrid: CSIC, 1984), 26-28.

${ }^{34}$ El 13 de abril de 1624 «Recibiose a Joan Bauptista Sánchez, pintor, por cofrade». Ver en Mercedes Agulló y Cobo, Más noticias sobre pintores madrileños de los siglos XVI al XVII (Madrid: Instituto de Estudios Madrileños, 1981), 182.

35 Casado en agosto de 1618 con María Márquez, los cuatro hijos de la pareja, nacidos entre 1619 y 1624, fueron bautizados todos en dicha iglesia, señal de que era parroquiano de la misma. Ver Matías Fernández García, Parroquia madrileña de San Sebastián. Algunos personajes de su archivo (Madrid: Caparros editores, 1995), 190-191.

36 Pérez Sánchez, "Los pintores escenógrafos", 68.

${ }^{37}$ Ver Ana María Sánchez Salcedo, "Que no ha de ser obra de encantamiento sino invención de ingeniero", en Théâtre, Musique et Arts dans les Cours Européennes de la Renaisance et du Baroque. Actas du Congres International. Varsovia 23-28, sept. 1996, ed. K. Sabik, (Varsovia: Universidad de Varsovia, 1997), 309-319, 316-317. Según esta investigadora fue la Comedia de Merlín. Peale, quien da por segura 
lienzos «de arquitectura» ${ }^{38}$ para la representación de Casa con dos puertas de Calderón, hecha en 1635 por la compañía de Antonio de Prado a los reyes. Los documentos palaciegos revelan que se trataba de un artista bastante cualificado y que sus trabajos no eran tan «modestos». De hecho, también en 1629, aunque no sabemos para qué obra, pintó

dos pilares y una cornisa, un escudo de armas reales, una nube çeleste y dos medios aros grandes pintados de quatro colores, vn lienço de peñasco grande, un globo pintado por dentro y por de fuera, con una nube abaxo $=$ dos leones grandes, dos águilas con su corona y una valla para el torneo ${ }^{39}$.

La ejecución de este tipo de elementos me inclina a afirmar que se trata del mismo Juan Bautista Sánchez que, asociado a Juan de Barahona, hizo en 1632 la tarasca del Corpus madrileño «conforme al dibujo que a[n] entregado» ${ }^{40}$. Con los años parece haber alcanzado mayor pericia, especializándose en «perspectivas»y arboledas como las que hizo para las Carnestolendas de $1640^{41}$ y constituyen también la parte esencial del trabajo que se le encomendó en 1655. En sus últimos años actuó, además, como tasador de pinturas ${ }^{42}$.

la autoría de Lotti para la escenografía de esta comedia, aporta documentación palaciega que sitúa la representación en el Jardín de los Naranjos, que formaba parte del Jardín de la Reina. C. George Peale, "Sobre la fecha y la escenografía de Palmerín de Oliva, del Doctor Juan Pérez de Montalbán", Criticón 123 (2015), 167-191. En línea: https://doi.org/10.4000/criticon.1571 (consultado el 14 diciembre 2020)

38 Ver María Luisa Caturla, Pinturas, frondas y fuentes del Buen Retiro (Madrid: Revista de Occidente, 1947), 34.

39 AGP, Felipe IV, 1 bis, fol. 612. Ver también Sánchez Salcedo, "Que no ha de ser obra”, 318.

40 Ver el contrato en Norman D. Shergold y John E. Varey, "Documentos sobre los autos sacramentales en Madrid hasta 1636", Revista de la Biblioteca, Archivo y Museo del Ayuntamiento de Madrid, XXIV, nº 69 (1955), 203-314, 272-273. Barahona también había participado en «la tramoya que se hizo a sus Majestades en el Jardín de los Naranjos de la comedia de Merlín el año pasado de mil y seiscientos y veinte y nueve», realizando, precisamente, «un dragón, todo el desnudillo pintado y plateado y dorado, y se hizo para él cabeza nueva y las alas de hilo de alambre = más una cabeza grande de dragón que le entraba a una mujer en la cabeza = y puso doce varas de bocací pintado, con ojos de oro y plata para el vestido de la dicha cabeza [...] lo cual fue para la comedia que representaron los criados de la Reina Nuestra Señora el año pasado de mil y seis cientos y veinte y nueve». Data de destajos del pagador Juan Gómez Mangas del año 1629. Carta de pago firmada el 21/6/1631. AGS, CMC, 3-EP, leg. 697. Ver Peale, "Sobre la fecha”, 20, nota 19.

${ }^{41} \mathrm{El} 14$ de marzo de 1640 se consigna el almacenamiento en la Munición del Retiro de «Diez y siete lienzos, treze de prespetibas, quatro arboledas de seis pies de ancho y veinte y uno de alto que an echo y entregado Juan de Solis y Juan Bautista Sanchez, pintores.» AGP, Administrativa, C ${ }^{\text {a }}$ 11730, expte. 7, s.f. Ver Fuentes para la historia del teatro en España XXIX. El teatro palaciego en Madrid: 1586-1707. Estudio y documentos, ed. Margaret R. Greer y John. E. Varey, (London: Támesis Books, 1997), 88 (doc. 7).

42 En 1657, cuando vivía «en la calle de Santa Ysabel, en casas de doña Juana de Vergara», tasó como «maestro pintor» las de Mateo Alberto de Ferrera, y tres años más tarde, en 1660, las que quedaron por la muerte del maestro pasamanero Lázaro Sánchez. AHP, Po 6056 (Ferrera) y Po 10005 (Sánchez). Ver en Agulló y Cobo, Más noticias, 182. 
Formado como pintor escenógrafo en la época de Cosme Lotti, estaba, por tanto, perfectamente capacitado para colaborar en 1655 con el nuevo ingeniero teatral. Tres fueron los «teatros» para la comedia de Solís que se le encargaron, obligándose Sánchez «a cumplir y entregar esta pintura a toda satisfacion para 8 de mayo en precio de 11.000 Rs., pag[a]dos en tres tercios, vno en contado, otro a la mitad de la obra y el otro el día que la a de entregar pena de perderla si no cunpliere» ${ }^{43}$.

\section{a) «Selva de los Hados»}

Este «teatro $1^{\mathrm{o}}$ de la $1^{\mathrm{a}}$ jornada» (en 1658 fue, además, la primera mutación de la $2^{\text {a }}$ jornada) aparece mencionado simplemente como «Selva de los Hados» en la Relación de 1655, que no da más información sobre una escenografía bastante compleja en su realización definitiva, ya que cambiaba en tres ocasiones: la citada selva era reproducida en «los primeros bastidores», más «un bastidor de árboles cortados que cubre la mitad del tablado». Éste bastidor desaparecía tras disparar Amor una flecha, dejando a la vista «un monte de peñascos» que «ba de ocupar toda la escena de una parte a otra», y que, a su vez, desaparecía volando «en movimiento apresurado», descubriéndose en el tablado a Venus con seis ninfas ${ }^{44}$. Podemos hacernos una idea de su apariencia (Fig. 1) combinando dos escenas de Andrómeda y Perseo: la gruta de Morfeo (Lám. V, fol. $39 \mathrm{v})$ guarnecida de «peladas peñas en la que se iniciaba la $2^{\mathrm{a}}$ jornada, y la «frondosa selva» (Lám. VIII, fol. 70v) que Palas sobrevuela en un carro:

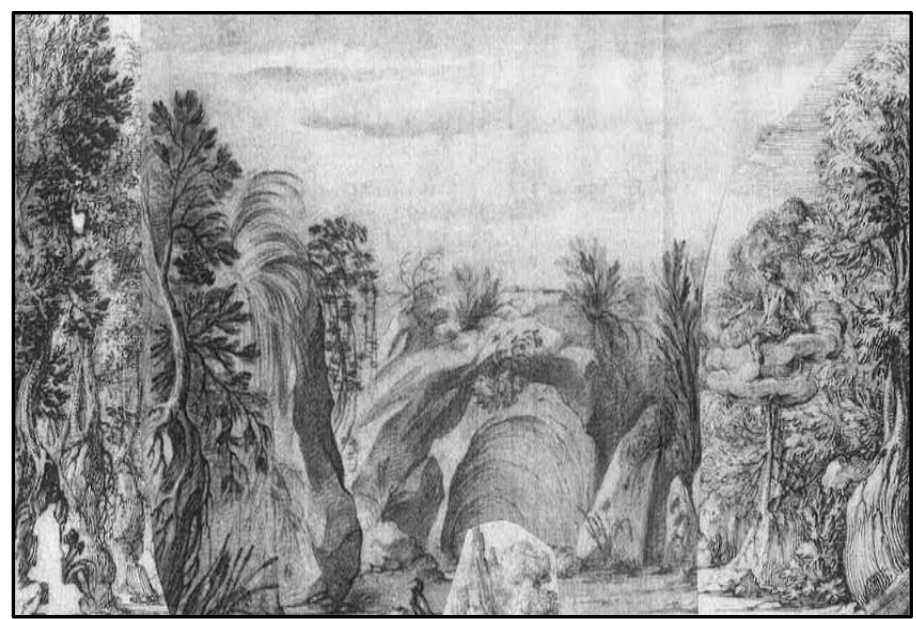

Fig. 1- Propuesta de reconstrucción para el «teatro $1^{\circ}$ de la $1^{\mathrm{a}}$ jornada»: «Selva de los Hados» (composición de M.A. Flórez)

43 ADA, Carpio, Caja 145, no 13, «Relación de los Maestros pintores».

${ }^{44}$ Ver Puchau, Antonio de Solís, 87, 96 y 100; y Sánchez Regueira, Comedias, 51, 57-58 y 61. Para mayor claridad mantengo las cursivas en las acotaciones de la representación de 1658, diferenciándolas así de las referencias de la Relación de 1655, que pongo entre comillas. 


\section{b) «Chozas»}

Descrita en la Relación de 1655 como «arboles, bosques y choças» (era el «teatro $1^{\circ}$ de la $3^{\mathrm{a}}$ jornada»), en la versión de 1658 esta escena ( $8^{\mathrm{a}}$ mutación, jornada III) estaba «compuesta de chozas y perspectivas rústicas. $Y$, al mismo tiempo, cae el bastidor del foro en que se ba de ver una choza con adornos rústicoss ${ }^{45}$. Tuvo que ser, por tanto, muy semejante a las «rústicas caserías, choças y cauañas, que cubiertas de nieue hermoseauan, con desaliño y estrañeça, los ribaços de sus riscos, montes y breñas» (Lám. III, f. 12v) en las que se iniciaba la primera jornada de Andrómeda y Perseo.

\section{c) «Marina»}

La Relación de 1655 especifica que «el teatro $2^{\circ}$ de la $3^{a}$ jornada» debía ser una «marina y puertos con dos palacios», que podría tener cierta similitud con un dibujo de Baccio de la vista de un puerto con veleros conservada en el Gabinetto Disegni e Stampe de la Galería de los Uffizi (Florencia) ${ }^{46}$. Puede que aquí se modificase en parte el planteamiento original ya que, según la acotación de 1658, esta $9^{a}$ mutación fue un «Puerto de Man» cuya «mitad -que ha de ser terrestre - de escollos y montañas y la otra mitad de un puerto de mar con un coloso a imitación del de Rodas». Se supone que en una mitad había olas fingidas ya que en «medio de las aguas» debía verse a Venus en una concha rodeada de ocho sirenas con instrumentos, que iban acercando a la diosa hacia la parte delantera del tablado ${ }^{47}$. Es posible que el resultado final pudiera parecerse a la combinación que propongo (Fig. 2) de la marina de los Uffizi con la lámina X (f. 87) de Andrómeda y Perseo, sustituyendo al monstruo por Venus y sus sirenas y el torreón del fondo por el coloso.

45 Aparecía tras el v. 2466. Ver Puchau, Antonio de Solís, 187-188 y Sánchez Regueira, Comedias, 121. 46 Ver http://www.zeno.org/Kunstwerke/B/Baccio+del+Bianco $\% 3 \mathrm{~A}+$ Hafenansicht + mit + Segelschiffen. (consultado el 19 de octubre de 2020).

47 Ver Puchau, Antonio de Solís, 203 y Sánchez Regueira, Comedias, 131. 


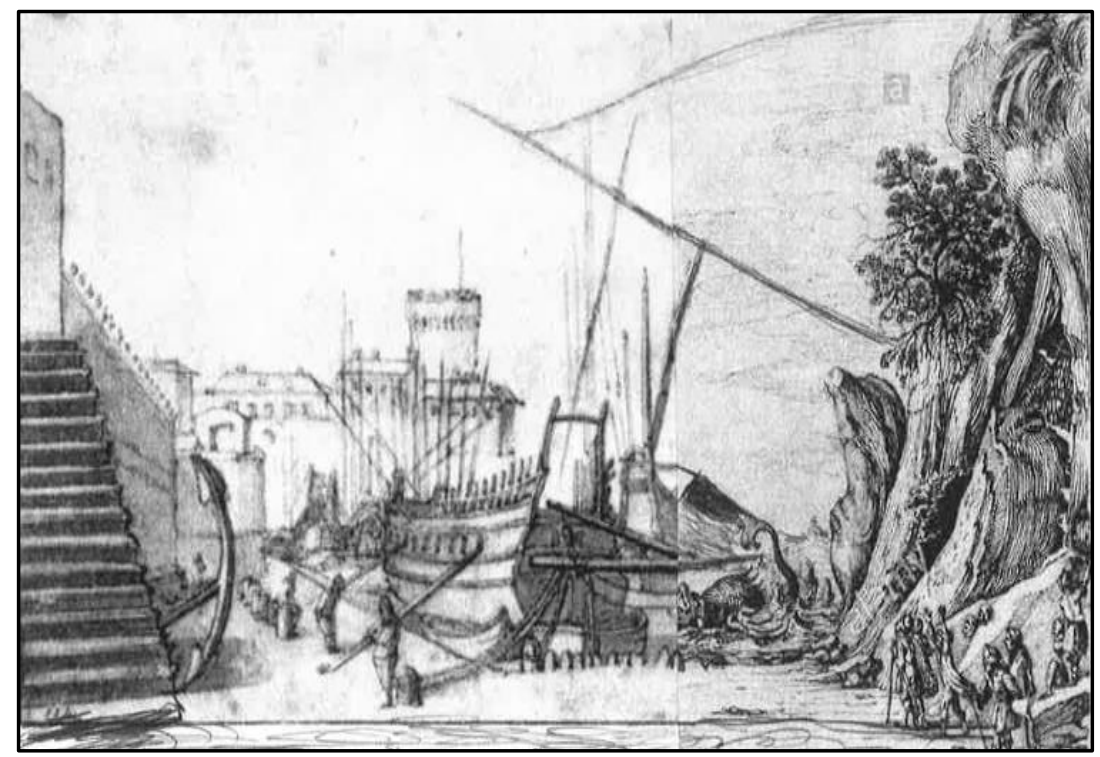

Fig. 2- Propuesta de reconstrucción para "el teatro $2^{\circ}$ de la $3^{a}$ jornada": "Marina" (composición de M.A. Flórez)

Lo más interesante en este caso es la concepción escénica en dos mitades distintas, que parece apuntalar la autoría de Baccio, al que se debe el primer ejemplo de escenografía asimétrica en España del que tenemos noticia y prueba fehaciente. Concretamente, la primera mutación de la jornada III de Andrómeda y Perseo, que «Era de una parte, el un costado della [...] casa de campo de noble; y, para que mas el sitio lo calificase, eran de la otra, en el otro costado, amenos jardines que la hermoseauan» ${ }^{48}$. Pero no fue el único; posiblemente Baccio diseñó algo parecido a lo descrito en Triunfos para El golfo de las sirenas (1657) de Calderón. Aunque las acotaciones no dan ninguna indicación sobre el tipo de escena en la que se desarrolla la acción, encontramos algunas pistas en el texto. Así, en la loa el personaje de Alfeo dice claramente que «quantos náufragos echa / a esta playa el mar, la siguen / venciendo el ceño a esa cuesta / que en vez de Alcázar, remata / en una profunda cueva» ${ }^{49}$. Al iniciarse la comedia la acotación indica que «Salen en lo alto Escila, vestida de caçadora, y Caribdis de sirena, cada una por su partes $\rangle^{50}$, de lo que se deduce que Escila aparece sobre lo alto del risco rematado por una cueva mientras que, en el lado opuesto, Caribdis surge del mar.

${ }^{48}$ Lám IX, f. 75v. Ver Andrómeda y Perseo. Ed cit. p. 132.

${ }^{49}$ Pedro Calderón de la Barca, El golfo de las sirenas, ed. Sandra L. Nielsen (Kassel: Reichenberger, 1989), 74, vv. 266-270. Las cursivas son mías. Denominada «égloga piscatoria», es una zarzuela en un acto o jornada, estrenada el 17/1/1657 en el palacete de la Zarzuela. Presenta la peculiaridad de que loa, fiesta y mojiganga forman una unidad y, al parecer, se desarrollan en la misma mutación.

${ }^{50}$ Calderón, El golfo, 79. 


\section{JUAN DE TOLEDO}

Muy diferentes entre sí eran las dos mutaciones encargadas a Juan de Toledo (c. 1615-1665) ${ }^{51}$, el único de estos tres pintores-escenógrafos citado por Lázaro Díaz del Valle, que le considera «muy buen pintor». Además de estimar sus grandes lienzos, le reconoce «particular genio y gracia para pintar batallas y caballos, y por sus obras ha adquirido grande opinión en esta corte y lo que en esta arte ha llegado a saber lo ha granjeado en la escuela de Italia» ${ }^{52}$. Palomino también le alaba como pintor de «marinas, y batallas con singular excelencia», y maestro del claroscuro, técnica que pudo aprender durante su estancia en Italia. Aunque no menciona que se dedicase a la escenografía, Toledo debía tener sólidos conocimientos de perspectiva ya que, además de pintar varios retablos, colaboró con la historia de Santo Tomás en el «techo de la iglesia nueva del Colegio de Atocha [...] aquel sitio, para donde se eligieron los primeros nombres que había entonces» en la Corte ${ }^{53}$.

Natural de Lorca (Murcia), y soldado antes que pintor ${ }^{54}$, Pérez Sánchez ${ }^{55}$ le incluye en el grupo de pintores que se especializaron en géneros nuevos (paisajes, batallas, bodegones ${ }^{56}$, etc.) destinados a una clientela de clase media urbana ${ }^{57}$ asentada en la corte, formada principalmente por la nobleza menor, funcionarios y una incipiente burguesía que incluía a los principales actores de las dos compañías estantes en la villa ${ }^{58}$. A este grupo podría ir destinado un Incendio de Troya de pequeño

${ }^{51}$ Casado con Catalina de Amor, murió el $1^{\circ}$ de febrero de 1665 en el Hospital de Corte. Fue enterrado de limosna en la iglesia de San Sebastián. Ver Fernández García, Parroquia madrileña, 194.

52 Como ejemplo de lienzos de grandes dimensiones cita uno «de la Concepción de Nuestra Señora con mucho triunfo de ángeles en gloria [y] con la Santísima Trinidad, arriba de diez varas castellanas de alto, y la figura principal tiene tres de alto», realizado para «la iglesia de las monjas de Don Juan de Alarcón.» Ver en David López García, Lázaro Díaz del Valle y las Vidas de pintores de España (Madrid: Fundación Universitaria, 2008), 275-276.

53 Palomino, El Parnaso Español, 200-201. Según Díaz del Valle pintó «la historia de cuando Santo Tomás ofreció sus escritos a Nuestro Señor Jesucristo». López García, Lázaro Díaz del Valle, 276. Para su biografía ver José Luis Morales Marín, "El capitán pintor Juan de Toledo", Goya 134 (1976), 80-86, y María Victoria Caballero Gómez, Juan de Toledo. Un pintor en la España de los Austrias (Murcia: Real Academia Alfonso X el Sabio, 1985).

${ }^{54}$ Según Díaz del Valle, su padre, Miguel de Toledo, fue también pintor. López García, Lázaro Díaz del Valle, 275.

55 Alfonso Emilio Pérez Sánchez, Pintura barroca en España (1600-1750) (Madrid: Cátedra, 1992), 242.

${ }^{56}$ Muchos de ellos combinaban estos géneros con los decorados. Fue el caso de José de Ciezar, pintor ad honorem del rey. Además de sobresalir en países y flores, «que las hacía con superior excelencia», mostró una «excelente habilidad en las mutaciones del coliseo del Buen Retiro». Palomino, El Parnaso Español, 328

${ }^{57}$ Es el caso de $\mathrm{D}^{\mathrm{a}}$ Isabel de Villegas, propietaria de varias casas en Madrid, que alquilaba, entre otros, a pintores. En sus capitulaciones matrimoniales con Juan Álvarez, que incluyen varias pinturas, aparecen «dos uatallas de Juan de Toledo» tasadas en 200 reales y «otra batalla del dicho, más gradezica» (132 rs.) AHPM, Po. 9408, f. 7-10. Ver Agulló y Cobo, Más noticias, 216-217 (inventario) y 97 (Isabel como casera).

${ }^{58}$ Encargadas, precisamente, de representar fiestas reales como Triunfos de Amor y Fortuna. Para la posesión de cuadros por parte de los actores y sus posibles relaciones con pintores-escenógrafos ver 
tamaño $(0,36 \times 0,55)$ hoy perdido, que le atribuye el marqués de Saltillo y que López Torrijos cree muy probable fuese «un cuadro con personajes accesorios dentro de un gran marco de arquitectura ${ }^{59}$. Los múltiples lienzos de batallas que se le atribuyen están, según Pérez Sánchez, más próximos a la pintura flamenca que a la romana o napolitana, mientras que sus obras religiosas le muestran «todavía con la gravedad de Carducho, pero algo tocado ya del barroquismo de Francisco Rizi» ${ }^{60}$.

Con estos antecedentes cuadran sólo pasablemente las dos mutaciones que se le encargaron por un precio de 7.300 reales, «pag[a]dos a los plaços y con la pena que la de arriua»y fecha de entrega el 12 de mayo ${ }^{61}$.

\section{a) «Selva de Diana»}

La primera, única que finalmente se reutilizó, era el «teatro $2^{\circ}$ de la $1^{\mathrm{a}}$ jornada», mencionado como «Selva de Diana». En este caso la Relación de 1655 nos da más indicaciones sobre esta $2^{a}$ mutación que las acotaciones de 1658 («Descúbrese la segunda mutación de la Selva de DLANA») ${ }^{62}$, ya que especifica que Toledo debía decorarla «con árboles zipreses y animales de mármoles». Es posible que tanto ésta como la «Selva de los Hados» en la que se inició la comedia, fuesen semejantes a la «frondosa selva» diseñada por Baccio para la segunda jornada de Andrómeda y Perseo ${ }^{63}$.

b) «Ruinas de edificios»

Este «teatro $2^{\circ}$ de la $2^{a}$ jornada» según la Relación de 1655, parece que se suprimió $^{64}$ en 1658 ya que en las acotaciones se dice que la $5^{\text {a }}$ mutación fue el «Salón reali del palacio de Amor ${ }^{65}$, que debía ejecutar Rico.

\section{FRANCISCO RICO}

Pese a sernos desconocido, posiblemente por tratarse del artista más cercano al concepto de pintor-artesano ${ }^{66}$, el trabajo encomendado a Francisco Rico fue el más extenso. Además de cuatro mutaciones para la obra principal, tenía que encargarse

\footnotetext{
María Asunción Flórez Asensio, “"Que más parecía casa de título que de particular». Actores y pintura en el Madrid del Siglo de Oro", Bulletin Hispanique 118-2 (2016): 647-672.

${ }^{59}$ Rosa López Torrijos, La mitología en la pintura española del Siglo de Oro (Madrid: Cátedra, 1985), 226.

${ }^{60}$ Pérez Sánchez, Pintura barroca, 256.

${ }^{61}$ ADA, CARPIO, Caja 145, no 13, Relación de los Maestros pintores.

62 Ver en Puchau, Antonio de Solis, 115 y Sánchez Regueira, Comedias, 71.

${ }^{63}$ Lámina VIII, f. 70v. Ver ed. cit. p. 112.

${ }^{64}$ Es probable que Solís diese un nuevo enfoque a esta parte de la obra para su estreno en 1658.

65 «se muda el teatro en un Salón Real, adornado rica y vistosamente.» Puchau, Antonio de Solís, 141 y Sánchez Regueira, Comedias, 90.

${ }^{66}$ Este grupo, del que el ya citado Juan de Baraona parece haber sido un excelente representante, no se limitaba a pintar decorados; también se ocupaban de los elementos escénicos como nubes y carros para las tramoyas, y demás objetos del atrezo, como los encargados a Rico.
} 
también de la del «Prologo, templo del Sol» ${ }^{67}$, y de «todas las demasías que vbiere de pintura, en que se incluien carros, cauallos, nubes sueltas, colunas y cornisas de madera del frontispicio del Teatro». Todo por 34.000 reales, «pagados en los plaços de las part[i]das anteçedentes», estando obligado «a dar hecha y acauada toda esta pintura con las demasias que vbiere para 20 de mayo».

\section{a) «Palacio de la Fortuna»}

De las cuatro mutaciones de la fiesta que debía ejecutar, la primera — «teatro $3^{\circ}$ de la $1^{\text {a }}$ jornada»- era el «Palacio de la Fortuna». Según la acotación de 1658, constaba de dos partes: un telón que debía reproducir la fachada del «Alcázar de la Fortuna $^{68}{ }^{8}$, con una puerta practicable por la que desaparecían todos los personajes. Tras hundirse la portada «se descubre la mutación del Alcázar de la FORTUN $A$ adornada de diferentes empresas de la próspera y la adversa FORTUN $A{ }^{69}$. Es posible que la fachada se asemejase a la «fachada del inmenso edificio», un «palacio regio», de la última mutación de Andrómeda y Perseo ${ }^{70}$.

\section{b) «Sala Real»}

Primera de las dos mutaciones que Rico debía realizar para la jornada II, en la Relación de 1655 se la menciona cómo «el teatro $1^{\mathrm{o}}$ de la $2^{\mathrm{a}}$ jornada», aunque en 1658 pasó a ser la $2^{a}$ mutación de esta jornada II. Las acotaciones sólo indican que era «un Salón Real, adornado rica y vistosamentes ${ }^{71}$ ya que pertenecía al palacio con el que Amor obsequia a Psique.

\section{c) «Palacio y jardin de Psique»}

La $6^{\mathrm{a}}$ mutación de la obra según la Relación de 1655 era «el teatro $3^{\circ}$ de la $2^{\mathrm{a}}$ jornada, que es palacio y jardín de Psique» ${ }^{72}$. No obstante, lo realizado finalmente parece que fue bastante diferente pues en 1658 se introdujo aquí una nueva mutación. Las acotaciones la mencionan como «Mansión del Sueño» que, al abrirse el «bastidor del Foro», dejaba ver al fondo del escenario la «Gruta del Sueño» en la que podía verse a Diana y sus seis ninfas, todas dormidas, y a Morfeo «retratando a DIANAy, a los lados, la OCIOSID AD y la QUIETUD con instrumentos músicos, y el SILENCIO con el dedo en la

${ }^{67}$ No aparece en la Loa de 1658, para la que se ideó «de la mitad abajo jardín, y de la otra cielo, y en la tierra un Arco Triunfal con el nombre de Felipe, escrito en letras de oro» Ver Sánchez Regueira, Comedias, 59. Como era lógico, la loa se cambió al cambiar la ocasión celebrada.

${ }^{68}$ Ver en Puchau, Antonio de Solís, 124 y Sánchez Regueira, Comedias, 77. El cambio se produce tras los vv. 879 (aparición parcial) y 936 (se descubre toda la fachada).

69 Ver en Puchau, Antonio de Solís, 124 y Sánchez Regueira, Comedias, 77.

${ }^{70}$ Lámina XI (f. 98v). Ed. cit., p. 166.

${ }^{71}$ Ver en Puchau, Antonio de Solís, 141 y Sánchez Regueira, Comedias, 90.

72 «Plusique» en el texto original, error por Psique. 
bocas ${ }^{73}$; un espacio con su propia escenografía e iluminación dentro del marco general del escenario, que remitía claramente al modelo de cuadro dentro de un cuadro, incluyendo un personaje que enlaza la escena representada con el espectador. No podemos obviar que fuera también una idea original de Baccio, que ya había diseñado escenas semejantes tanto para La fiera, el rayo y la piedra (1652) (la gruta de las Parcas en la que éstas, según la acotación de la edición de la obra de 1664, debían aparecer «como las pintan») $)^{74}$, como para Andrómeda y Perseo: una «borrorosa gruta de Morfeo, cuyo lóbrego espacio guarnecían peladas peñas con algunos troncos de pálidos beleños y cipreses. Estaua, en lo profundo della, la deidad del sueño (significada en vn anciano viejo) recostada sobre vn riscor ${ }^{75}$.

La $7^{a}$ mutación, que según la acotación de 1658 era de «Jardín y teatro dividido en dos mansiones», sería, por tanto, la correspondiente al «Palacio y jardín de Psique», encargada a Rico como «teatro $3^{\circ}$ de la $2^{\text {a }}$ jornada». En su realización definitiva fue, sin embargo, una de las más complejas por tratarse nuevamente de una escena partida, mitad jardín, mitad retrete o sala privada. En la primera mitad, y «como fondo del jardín» aparecía una mansión en la que «se verá a ENDIMIÓN recostándose, turbado, en una fuente, y DLANA y sus NINFAS acechándole.» En la otra, "que será un retrete con alhajas y estrado», estaban Amor, Siques y las Ninfas del Amor ${ }^{76}$. Tras el v. 2094 «Desaparece el retrete y los bastidores que formaban la división de los teatros» quedando únicamente la «Mutación del jardín» con el Amor y Diana (cada uno con sus respectivas ninfas) a cada lado del tablado, «desde donde han de subir ambas deidades con sus coros a desaparecer por lo alto en una tramoya que represente el globo de la luna, ocupando todas, catorce personas, la frente del teatro y subiendo poco a pocos ${ }^{77}$.

\section{d) «Nubes»}

Rico también debía elaborar la última mutación de la obra: «el teatro $3^{\circ}$ de la $3^{\mathrm{a}}$ jornada que es todo de nubes». Era una típica «gloria di deità» ${ }^{78}$ que las acotaciones de 1658 mencionan simplemente como «Cielo» (10ªt mután) y que debido, sobre

${ }^{73}$ Ver en Puchau, Antonio de Solís, 157 y Sánchez Regueira, Comedias, 100. La nueva escena aparecía tras el v. 1726.

${ }^{74}$ Egido cree que Calderón y Baccio pudieron tener en mente Las Hilanderas de Velázquez, pintado posiblemente en la década de 1650. Aurora Egido. "Introducción" a su edición de La fiera, el rayo y la piedra de Calderón (Madrid: Cátedra, 1989), 11-121, 40.

${ }^{75}$ Lámina V, f. 39v. Ed. cit. p. 87. En ella se inicia la jornada $2^{\mathrm{a}}$.

${ }^{76}$ Ver en Puchau, Antonio de Solís, 166 y Sánchez Regueira, Comedias, 106. El teatro se «mudaba» tras el v. 1940.

77 Ver en Puchau, Antonio de Solis, 172 y Sánchez Regueira, Comedias, 110-111.

78 Así las describe el propio Baccio, que al llegar a España se encontró con la costumbre de que en medio de «una gloria di deità» se viesen «quattro guidoni vestiti di nero all'usanza con chitarre spagniole, cappa e spada [...] uso di qua, che quando tratto di levare questa usanza poco meno che non mi crocifiggono, dicendo che è impossibile che ballino senza quelle chitarre di dietro» Carta de 19/7/1653. Ver Bacci, "Lettere", 72. De los dibujos de Andromeda y Perseo (Lám. XI) se deduce que en apenas un año consiguió cambiar la costumbre vistiendo a los músicos conforme a la exigencia escénica. 
todo, a las tramoyas, supuso un coup de force por el elevado número de personas que debían moverse en ellas: en nubes y «por diferentes partes del aire» bajaron los coros del Amor y la Fortuna, Ganimedes, Morfeo, Céfiro y Flora. Tras abrirse el bastidor del foro se descubrió

en la frente el globo de la Tierra, el espacio del aire, y las cinco esferas de los planetas con sus estrellas y cifras transparentes. [...]. Y luego, sobre esta quinta esfera, el cielo de JÚPITER abierto, y en él se ve a JÚPITER en su trono y a los lados VENUS, DIANA, MERCURIO, el AMOR, la FORTUNA y otras deidades ${ }^{79}$.

\section{CONCLUSIONES}

Es muy de lamentar que Mariana de Austria, a cuya iniciativa se deben los dos únicos ejemplos de la puesta en escena de fiestas reales cantadas hispanas (Fortunas de Andrómeda y Perseo (1653) de Calderón y Los celos hacen estrellas (1673) de Juan Vélez de Guevara) ${ }^{80}$, no considerase oportuno enviar a Viena copia de la que debió ser una de las más espectaculares de su época, digna obra de un artista tan sumamente cualificado y polifacético como lo era Baccio del Bianco: pintor (al óleo y al fresco), arquitecto (civil y militar), escenotécnico (creaba escenografías y construía máquinas y autómatas), coreógrafo, figurinista y caricaturista, etc. ${ }^{81}$. Poseía, además,

${ }^{79}$ Ver en Puchau, Antonio de Solís, 216-219 y Sánchez Regueira, Comedias, 140-142. El movimiento tiene lugar entre los vv. 3.153 a 3229. Tras el v. 3307 los dos coros de Amor y Fortuna, Morfeo y Ganimedes «desaparecen por lo alto cantando y representando». Ver en Puchau, Antonio de Solís, 222 y Sánchez Regueira, Comedias, 144.

${ }^{80}$ Escrita en 1672 para celebrar los años de la Reina, fue representada en el Salón Dorado del Alcázar con escenografía de Herrera el Mozo que, como ya había sucedido con Baccio, hizo las acuarelas de las mutaciones que se enviaron a Viena. Allí se conservan en la Oesterreichisches Nationalbibliothek. Sabemos que se le pagaron 1.100 reales por este trabajo. AGP, Administrativa, $C^{a}$ 9407, expte. 5, fo 656r. Para su biografía ver Palomino, El Parnaso Español, 281; Barbeito, "Francisco de Herrera el Mozo y la comedia Los celos hacen estrellas", en El Real Alcázar de Madrid, dir. Fernando Checa, (Madrid: Nerea, 1994), 172; Pérez Sánchez, Carreño, Rizzi, Herrera; y del mismo autor "Herrera, Francisco de. El Mozo", en Diccionario Biográfico Español (Madrid: RAH, 2011), vol. XXVI, 82-84. La actividad de Herrera como escenógrafo es poco conocida. Además del «teatro pintado q[ue] hiço en el Salón de Palacio» en 1672 para la comedia representada para celebrar los años del rey (se le libraron 20.000 reales), en 1673 se ocupó de «pintar y acomodar» las dos comedias de las Carnestolendas. En 1674 diseñó las mutaciones de El mérito es la corona de Salazar y Torres, representada en palacio el 22 de diciembre para festejar los años de la Reina, aunque los decorados fueron ejecutados por Juan Fernández de Laredo. Ver AGP Administrativa, C ${ }^{a}$ 9407, expte. 1, (1672) y C ${ }^{\text {a }} 9408$ expte. 3 sin foliar (1673 y 1674).

81 Era también cartonista de tapices, modelista de vajillas, diseñador de orfebrería y mobiliario. Ver Baldinucci, Notizie, 30-31; Dizionario Biografico, 348-349; Matteolli, Anna, "Un contributo a Baccio del Bianco", Paradigma 5 (1983), 73-78, 75; Maestre, "Calderón de la Barca-Baccio", 241 y "Baccio del Bianco: Aportaciones a la escena áurea española”, en En torno al teatro del Siglo de Oro. Actas Jornadas IX$X$ (Almería: Instituto de Estudios Almerienses, 1995), 53-69, 55; Susana Hernández Araico, "Baccio del Bianco y sus anticipos escenográficos en pinturas florentinas", en Memoria de la palabra. Actas del Sexto Congreso de la Asociación Internacional Siglo de Oro, Burgos-La Rioja (2002), 2 vols., ed. María Luisa Lobato y Francisco Domínguez Matito, (Frankfurt am Main/Madrid: Vervuert/Iberoamericana, 2004), vol. II, 1019-1028; Măgureanu, Ioana, "Baccio del Bianco and the cultural politics of the Medici 
habilidades tan importantes de cara a su actividad teatral como compositor de música, instrumentista de cuerda y de viento, cantante (tenor), comediógrafo y actor. Un excelente representante, en definitiva, de un grupo de artistas con vastos y variados conocimientos artísticos y técnicos, puestos al servicio de la política de representación de los soberanos, cuya contratación se convirtió en un éxito diplomático tanto para el monarca contratante como para el príncipe que lo recomendaba y enviaba. Sin embargo, y a diferencia de los pintores-escenógrafos, estos profesionales se limitaban a la concepción intelectual, por lo que no parecen haberse implicado físicamente en la ejecución de los decorados ${ }^{82}$. Este trabajo desdeñado inicialmente por muchos artistas pese a su gran dificultad técnica- se encomendó en una primera época a pintores de segundo, y aun de tercer orden. Sólo avanzada la segunda mitad del siglo, al agudizarse la crisis económica en los últimos años del reinado de Felipe IV, encontraremos artistas de mayor renombre, al tiempo que parece establecerse una suerte de especialización en el tipo de mutaciones realizadas por cada uno conforme a sus habilidades ${ }^{83}$.

Triunfos de Amory Fortuna es, por tanto, un magnífico ejemplo de la evolución en este tipo de trabajos. Encomendada inicialmente la ejecución de sus decorados a artistas que hoy nos son prácticamente desconocidos, clara señal de su irrelevancia en el panorama artístico de la corte, ello no implica falta de habilidad técnica por parte de los mismos. Así lo demuestra que en 1658 fueran finalizados por uno de los máximos exponentes de la pintura madrileña de la época: Francisco Rizi, aunque

court", REV. ROUM. HIST. ART, Série BEAUX-ARTS, TOME XLVIII, P. 13-26, Bucarest, 2011. Edición electrónica, http:// www.istoria-artei.ro/resources/files/RRHA2011-Art02-I. Magureanu.pdf. (consultada el 19 octubre 2020).

${ }^{82}$ Pese a reconocer el entusiasmo que despierta su trabajo, Baccio refleja cierto desencanto con su posición en la corte madrileña: «si bene molte promesse ma son in aria, eppure que nos posso tener maggiori protettori di quelli mi tengo che sono D. Luigi e su figliolo, vero è che se di quando in quando avessi amico o padrone che mi raccomendassi, le cose si ponerebbero un poco meglio» Carta de 3/3/1656 a Fernando II, con referencias a Pico y Canente. Ver Bacci, "Lettere", 77. La diferencia de estatus entre un dramaturgo como Calderón y el italiano se percibe claramente en la forma en la que León Pinelo cita a ambos al dar noticia del éxito de La fiera, el rayo y la piedra. Siendo el poeta «D. Pedro Calderón de la Barca, Cavallero del Abito de Santiago», el «executor de las apariencias [es] el Vagio italiano». Antonio León Pinelo, Anales de Madrid (desde el año 447 al de 1658). Cito por Aurora Egido, "La puesta en escena de La fiera, el rayo y la piedra de Calderón, según la edición de 1664", en La escenografía del teatro barroco, ed. A. Egido (Salamanca: UIMP, 1989), 161-184, 163.

${ }^{83}$ Lorenzo Montero (hacía 1684) se especializó «en mutaciones de arboleda, jardín, u otras, donde hubiese algunos festones de flores, jarrones, o guirnaldas»; Bartolomé Pérez que «Asistió también mucho tiempo a las funciones del Coliseo, y casi siempre que se pintaba cortina, lo hacía él, porque tenía especial gracia y primor para ello». Palomino, El Parnaso Español, 379 (Montero) y 315 (Pérez). No obstante, el pintor-artesano no desapareció. Podemos verlo en Leonardo Alegre, pintor y «maestro esculto»», autor de varias tarascas para el Corpus madrileño, que colaboró con Herrera en la obra representada en 1672 para celebrar los años de Carlos II. Ocho años más tarde le encontramos encabezando la lista de los «Pasteros» que en 1680 participaron en la puesta en escena de Hado y divisa de Leónido y Marfisa, última fiesta real de Calderón, representada en 1680 para celebrar el primer casamiento del monarca. Ver Fuentes para la bistoria del teatro en España I. Representaciones palaciegas: 16031699, Estudio y documentos, ed. Norman D. Shergold y John E. Varey (Londres: Támesis Books, 1982), 129. 
todavía bajo la supervisión, eso sí, de otro arquitecto-ingeniero italiano: Antonio María de Antonozzi, al que se atribuyó todo el mérito, una situación que parece haberse invertido en el reinado de Carlos $\mathrm{II}^{84}$.

Lamentablemente, al no haberse conservado ninguno de los diseños originales, no podemos saber en qué medida Baccio del Bianco contribuyó al éxito de una fiesta con la que la Monarquía Hispánica celebró el nacimiento de su heredero y renovó su prestigio, demostrando ante súbditos, aliados y enemigos que todavía era una potencia europea.

\footnotetext{
${ }^{84}$ Especialmente tras la llegada a Madrid hacia 1679 del pintor-ingeniero-escenógrafo valenciano José Caudí, colaborador del boloñés Dionisio Mantuano, afincado en la villa y corte ya «en tiempos del señor Marques de Heliche» como «Ingeniero para las tramoyas, y mutaciones de las comedias [...] porque era también gran arquitecto». Pese a esta afirmación de Palomino, parece que Caudí actuaba como ingeniero y escenógrafo, mientras que el boloñés se ocupaba de pintar los decorados. Así se desprende de las cuentas de Faetón, representada el 22 de diciembre de 1679 para celebrar el cumpleaños de Mariana de Austria. Según las mismas a Mantuano, que dirigía un equipo de ocho oficiales, se le pagaron 200 ducados, mientras que a Caudí, que contaba únicamente con dos mozos, se le asignaron 150 ducados «por el trabajo que tuvo en hacer y dibujar todas las apariencias». Fuentes I: 95 y 97; Palomino, El Parnaso Español: 273. La situación se repitió con Hado y divisa de Leónido y Marfisa, última fiesta de Calderón (cobró 5.500 reales). Escrita para celebrar el matrimonio de Carlos II con María Luisa de Orleans, se representó durante las Carnestolendas de 1680 en el Coliseo del Buen Retiro, restaurado para la ocasión. Según las cuentas, a Mantuano se le pagaron 16.500 reales «por lo que ha trabajado en el dibujo y pintura del techo del Coliseo», mientras que a Caudí se le dieron 11.000 reales «por haber trazado las tramoyas y teatro de esta fiesta y ejecutádoles». Fuentes I: 126 y 133. La mayoría fueron realizadas por Fernández de Laredo, cabeza de una «compañía», por 22.000 reales. Otros pintores fueron Antonio de Castrejón (10.200 reales) y Josep García (20.500 reales). Fuentes I: 132.
} 


\section{ANEXO}

ARCHIVO DUQUE DE ALBA (ADA), CARPIO, Caja 145, n 13. Pagos a pintores por escenografía ${ }^{85}$ (8-IV-1655):

Relación de los Maestros pintores que se an encargado y an tomado por su quenta a toda costa la obra de pintura, que se a de hacer para las apariencias y tramoyas de la comedia que se a de representar en el Coliseo de buen retiro en este presente año de 1655 a la fiesta de los años del Rey n[uest]ro señor en conformidad de lo ajustado con ellos por el Marques de Liche mi s[eñ]or=

\section{Juan Bap[tis]ta Sanchez}

Esta obligado a cumplir y entregar esta pintura a toda satisfacion para 8 de mayo en precio de 11.000 Rs pag[a]dos en tres tercios, vno en contado, otro a la mitad de la obra y el otro el dia que la a de entregar pena de perderla si no cunpliere $=$ 11.000.-

Esta oblig[a]do a cumplir y entregar esta pintura para 12 de mayo en precio de 7.300 Rs. pag[a]dos a los plaços y con la pena que la de arriua $=$ 7.300.

18.300.-

Esta obligado a dar hecha y acauada toda esta pintura con las demasias que vbiere para 20 de mayo en preçio de 34.000 Rs. pagados en los plaços de las part[i]das anteçedentes= 34.000.-
El teatro $1^{\circ}$ de la $1^{\mathrm{a}}$ jornada que es de las selbas de los hados.

El teatro $1^{\circ}$ de la $3^{a}$ jornada que es de Arboles Bosques y choças.

El teatro $2^{\circ}$ de la $3^{a}$ jornada que es de Marina y puertos con dos Palacios.

\section{Juan de Toledo}

El teatro $2^{\circ}$ de la $1^{a}$ jornada que es de la selba de Diana con Arboles zipreses y Animales de Marmoles.

El teatro $2^{\circ}$ de la $2^{a}$ jornada que es Ruinas de Edificios.

\section{Francisco Rico}

El Prologo templo del Sol

El teatro $3^{\circ}$ de la $1^{a}$ jornada que es de

Palacio de la fortuna.

El teatro $1^{\circ}$ de la $2^{\mathrm{a}}$ jornada que es sala $\mathrm{R}[\mathrm{ea}] \mathrm{l}$.

El teatro $3^{\circ}$ de la $2^{\mathrm{a}}$ jornada que es

Palacio y jardín de plusique [sic por

Psique]

El teatro $3^{\circ}$ de la $3^{a}$ jornada que es todo de Nubes $=$

\footnotetext{
${ }^{85}$ Incluido entre varios papeles sobre el Buen Retiro cosidos y sin foliar.
} 
Todas las demasias que vbiere de pintura en que se incluien Carros, Cauallos, Nubes, sueltas, Colunas y Cornisas de madera del frontispicio del Teatro $=$

52.300.- Rs.

Por manera que monta la costa de toda la dicha obra de pintura en la conformidad referida cinquenta y dos mil y tre[s]cientos Reales.

F[ec]ho en Madrid a 8 de abril de 1655= Alejo de Escalada 


\section{REFERENCIAS BIBLIOGRÁFICAS}

Fuentes

Baldinucci, Filipo, Notizie dei professori del disegno da Cimabue in qua (Fiorenza: Batelli, 1847). Edic. facsímil Spes: Florencia, 1974, vol. V, 7-51.

Calderón de la Barca, Pedro, Andrómeda y Perseo. Edición filológica, crítica y escenotécnica de Rafael Maestre (Almagro: Museo Nacional del Teatro, 1994).

—, La fiera, el rayo y la piedra, ed. Aurora Egido (Madrid: Cátedra, 1989).

—, El golfo de las sirenas, ed. Sandra L. Nielsen (Kassel: Reichenberger, 1989).

Escrivense los sucesos de la Europa y otras partes desde el abril de 1652 hasta el Marco de 1653. BNE, Mss. 2384.

León Pinelo, Antonio, Anales de Madrid (desde el año 447 al 1658). BNE, MSS/18117. Acceso libre en línea a través de Biblioteca Digital Hispánica. Hay edición moderna con transcripción, notas y ordenación cronológica de Pedro Fernández Martin (Madrid: Instituto de Estudios Madrileños, 1971).

Méndez Silva, Rodrigo, Gloriosa celebridad de España en el nacimiento y solemne bautismo de su amado príncipe Felipe Próspero (Madrid, 1658). Acceso libre en línea a través de Biblioteca Digital Hispánica (Biblioteca Nacional de España).

Palomino, Antonio, El museo pictórico y escala óptica (Madrid: Aguilar, 1947).

-, Museo Pictórico y Escala Optica. III. El Parnaso Español Pintoresco Laureado (Madrid, 1724). Edición de Nina Ayala Mallory, Vidas [El Parnaso Español (Madrid: Alianza, 1986).

Ulloa y Pereira, Luis, Fiestas que se celebraron en la Corte por el Nacimiento de Don Felipe Prospero, Principe de Asturias. Hace memoria dellas al Rey nuestro señor (Dios le guarde) poniéndolas en las manos del Excelentísimo Señor Marqués de Heliche Don Luis de Ulloa, (Madrid, 1658). BNE, 3/40791.

Estudios

Agulló y Cobo, Mercedes, Más noticias sobre pintores madrileños de los siglos XVI al XVII (Madrid: Instituto de Estudios Madrileños, 1981).

Azcarate, José María, “Anales de la construcción del Buen Retiro”, Anales del Instituto de Estudios Madrileños I (1966): 99-135. 
Bacci, Mina, "Lettere inedite di Baccio del Bianco", Paragone 157 (1963): 68-77.

Barbeito, José Manuel, "Francisco de Herrera el Mozo y la comedia Los celos hacen estrellas", en El Real Alcázar de Madrid, dir. Fernando Checa, (Madrid: Nerea, 1994), 172.

Caballero Gómez, María Victoria, Juan de Toledo. Un pintor en la España de los Austrias (Murcia: Real Academia Alfonso X el Sabio, 1985).

Caturla, María Luisa, Pinturas, frondas y fuentes del Buen Retiro (Madrid: Revista de Occidente, 1947).

Chaves Montoya, María Teresa, El espectáculo teatral en la corte de Felipe IV (Madrid: Ayuntamiento de Madrid, 2004).

Diæionario Biografico degli Italiani (Roma: Istituto dell'Enciclopedia Italiana, 1988).

Egido, Aurora. "Introducción” a su edición de La fiera, el rayo y la piedra de Calderón (Madrid: Cátedra, 1989), 11-121.

-, "La puesta en escena de La fiera, el rayo y la piedra de Calderón, según la edición de 1664", en La escenografía del teatro barroco, ed. A. Egido (Salamanca: UIMP, 1989), 161-184.

Fernández García, Matías, Parroquia madrileña de San Sebastián. Algunos personajes de su archivo (Madrid: Caparros editores, 1995).

Ferrer Valls, Teresa, La práctica escénica cortesana: de la época del Emperador a la de Felipe III (London, Támesis, 1991).

Flórez Asensio, María Asunción, "El Coliseo del Buen Retiro en el siglo XVII: teatro público y cortesano", Anales de Historia del Arte 8 (1998): 171-195.

—, "El marqués de Liche: Alcaide del Buen Retiro y "Superintendente" de los Festejos Reales", Anales de bistoria del arte 20 (2010): 145-182.

-, "«Que más parecía casa de título que de particular». Actores y pintura en el Madrid del Siglo de Oro", Bulletin Hispanique 118-2 (2016): 647-672.

Fuentes para la bistoria del teatro en España I. Representaciones palaciegas: 1603-1699, Estudio y documentos, ed. Norman D. Shergold y John E. Varey (Londres: Támesis Books, 1982). 
Fuentes para la historia del teatro en España XXIX. El teatro palaciego en Madrid: 1586-1707. Estudio y documentos, ed. Margaret R. Greer y John E. Varey, (London: Támesis Books, 1997).

Frutos, Leticia, El templo de la fama. Alegoría del marqués del Carpio (Madrid: Fundación Caja Madrid-Fundación Arte Hispánico, 2009).

González-Román, Carmen, "El artista escenógrafo: una especialidad no reconocida en la Edad Moderna", en Correspondencia e integración de las Artes: XIV Congreso nacional de Historia del Arte (Málaga, 18-21 septiembre 2002), ed. Isidoro Coloma Martín, María Teresa Sauret Guerrero, Belén Calderón Roca, Raúl Luque Ramírez, (Málaga: Universidad de Málaga, 2003), vol. 1, 207-223. En línea: https://www.academia.edu/20001780/El artista escen \%C3\%B3grafo una especialidad no reconocida en la Edad Moderna, p. 3. (consultado el 14 diciembre 2020).

Hernández Araico, Susana, "Baccio del Bianco y sus anticipos escenográficos en pinturas florentinas", en Memoria de la palabra. Actas del Sexto Congreso de la Asociación Internacional Siglo de Oro, Burgos-La Rioja (2002), 2 vols., ed. María Luisa Lobato y Francisco Domínguez Matito, (Frankfurt am Main/Madrid: Vervuert/Iberoamericana, 2004), vol. II, 1019-1028.

López García, David, Lázaro Díaz del Valle y las Vidas de pintores de España (Madrid: Fundación Universitaria, 2008).

López Torrijos, Rosa, La mitología en la pintura española del Siglo de Oro (Madrid: Cátedra, 1985).

Maestre, Rafael, "Calderón de la Barca-Baccio del Bianco: un binomio escénico", Revista de Historia Moderna 11 (1992): 239-250.

-, "Baccio del Bianco: Aportaciones a la escena áurea española", en En torno al teatro del Siglo de Oro. Actas Jornadas IX-X (Almería: Instituto de Estudios Almerienses, 1995), 53-69.

Măgureanu, Ioana, "Baccio del Bianco and the cultural politics of the Medici court", REV. ROUM. HIST. ART, Série BEAUX-ARTS, TOME XLVIII, P. 13-26, BUCAREST, 2011. Edición electrónica, http:// www.istoriaartei.ro/resource s/files/RRHA 2011-Art 02-I. Magureanu.pdf

Massar, Phyllis Dearborn, "Scenes for a Calderón Play by Baccio delBianco" Master Drawings 15 (1977) 365-375.

Matteolli, Anna, "Un contributo a Baccio del Bianco", Paradigma 5 (1983): 73-78. 
Morales Marín, José Luis, “El capitán pintor Juan de Toledo”, Goya 134 (1976): 80-86.

Peale, C. George, "Sobre la fecha y la escenografía de Palmerín de Oliva, del Doctor Juan Pérez de Montalbán”, Criticón 123 (2015), 167-191. En línea: https://doi.org/10.4000/criticon.1571

Pérez Sánchez, Alfonso Emilio, Carreño, Rizzi, Herrera y la pintura madrileña de su tiempo (Madrid: Museo del Prado, 1986).

Pérez Sánchez, Alfonso E., "Los pintores escenógrafos en el Madrid del siglo XVII", en La escenografía del teatro barroco, coord. Aurora Egido, (Salamanca: UIMP, 1989), 61-90.

Pérez Sánchez, Alfonso E., Pintura barroca en España (1600-1750) (Madrid: Cátedra, 1992).

— "Herrera, Francisco de. El Mozo”, en Diccionario Biográfico Español (Madrid: RAH, 2011), vol. XXVI, 82-84.

-, "Rizi de Guevara, Francisco", en Diccionario Biográfico Español, (Madrid: RAH, 2013), vol. XLIII, 648-651.

Puchau de Lecea, María del Mar, Antonio de Solís y Rivadeneyra. Triunfos de Amor y Fortuna. Estudio y edición crítica, con transcripción poético-musical de las piezas conservadas de Lola Josa y Mariano Lambea (Aula Música Poética), (Alicante: Biblioteca Virtual Miguel de Cervantes, 2013), http://www.cervantesvirtual.com/nd/ark:/59851/bmc001v8

Salort Pons, Salvador, Velázquez en Italia (Madrid: Fundación Arte Hispánico, 2002).

Sánchez del Peral y López, Juan Ramón, “Antonio María Antonozzi, ingeniero de las comedias del Buen Retiro (1657-1662). Nuevos datos para la biografía de un inventor de "maravillosas apariencias", Archivo español de arte LXXX/319 (2007): 261-273.

Sánchez Regueira, Manuela, Comedias de Antonio de Solís (Madrid: CSIC, 1984).

Sánchez Salcedo, Ana María, "Que no ha de ser obra de encantamiento sino invención de ingeniero", en Théatre, Musique et Arts dans les Cours Européennes de la Renaisance et $d u$ Baroque. Actas du Congres International. Varsovia 23-28, sept. 1996, ed. K. Sabik, (Varsovia: Universidad de Varsovia, 1997), 309-319.

Serralta, Fréderic, "Nueva Biografía de Antonio de Solís y Rivadeneyra", Criticón 34 (1986): 51-157. 
Shergold, Norman D., A History of the Spanish Stage from Medieval times until the end of the Seventeenth Century (Oxford, Clarendon Press, 1967).

Shergold, Norman D. y Varey, John E., "Documentos sobre los autos sacramentales en Madrid hasta 1636", Revista de la Biblioteca, Archivo y Museo del Ayuntamiento de Madrid, XXIV, 69 (1955): 203-314.

Trambaioli, Marcella. "La escritura en colaboración en Elpastor Fido de Solís, Coello y Calderón", en Calderón y su escuela: variaciones e innovación de un modelo teatral. XV Coloquio Anglogermano sobre Calderón (Wrodaw, 14-18 de julio de 2008), ed. Manfred Tietz y Gero Arnscheidt, en colaboración con Beata Baczynska (Stuttgart: Franz Steiner Verlag, 2011), 493-521.

Vidales del Castillo, Felipe, "El VII marqués del Carpio y las letras" (Tesis doctoral, Universidad Complutense, 2016).

Recibido: 19 de enero de 2021 Aceptado: 26 de febrero de 2021 